\title{
CONTRATOS DE BIOPROSPECÇÃO E PROPRIEDADE INTELECTUAL: UMA ANÁLISE DAS MEDIDAS ALTERNATIVAS NO SISTEMA DE PATENTES PARA OTIMIZAR A PROTEÇÃO DA BIODIVERSIDADE
}

\section{BIOPROSPECTION CONTRACTS AND INTELLECTUAL PROPERTY: AN ANALYSIS OF ALTERNATIVES MEASURES IN PATENTS SYSTEM TO OPTIMIZE BIODIVERSITY PROTECTION}

\author{
${ }^{1}$ Nathalia Bastos do Vale Brito \\ ${ }^{2}$ Sébastien Kiwonghi Bizawu
}

\section{RESUMO}

O presente artigo objetiva analisar a existência de medidas alternativas suscetíveis de serem aplicadas ao sistema de patentes para potencializar a proteção da biodiversidade no âmbito dos contratos de bioprospecção, considerando os riscos concernentes à apropriação indevida de recursos biológicos e conhecimento tradicional associado. Partindo do método indutivodedutivo, pesquisa bibliográfica e análise de caso, observa-se que os contratos de bioprospecção podem proporcionar inúmeras desvantagens para os países fornecedores de recursos biológicos, sendo necessário um maior compartilhamento de benefícios entre as partes, seguido de um fortalecimento das legislações nacionais sobre acesso à biodiversidade e aumento da fiscalização das atividades de bioprospecção.

Palavras-chave: Biodiversidade, Bioprospecção, Patentes

\begin{abstract}
This article analyses the existence of alternatives measures susceptible of appliance in the patent system to promote biodiversity protection within the bioprospection contracts, considering the risks related to misappropriation of biological resources and traditional knowledge. Through the inductive-deductive method, bibliographic research and case analysis, it is observed that the bioprospection contracts can provide numerous disadvantages to countries that provides biological resources. It is necessary a greater benefit sharing between the parties, followed by a strengthening of nationals laws about access to biodiversity and increase the bioprospection activities fiscalization.
\end{abstract}

Keywords: Biodiversity, Bioprospection, Patents

\footnotetext{
${ }^{1}$ Mestranda em Direito Ambiental e Desenvolvimento Sustentável pela Escola Superior Dom Helder Câmara, Belo Horizonte, Minas Gerais, (Brasil). E-mail: nathaliabvbrito@gmail.com

${ }^{2}$ Doutor em Direito Internacional pela Escola Superior Dom Helder Câmara, Belo Horizonte, Minas Gerais, (Brasil). Professor de Direito Internacional Público e Privado na Escola Superior Dom Helder Câmara. E-mail: kiwonghi@ domhelder.edu.br
} 


\section{INTRODUÇÃO}

A biodiversidade é um dos componentes do meio ambiente, englobando a flora, a fauna e as interações existentes que garantem o equilíbrio dos ecossistemas, incluindo-se nestas interações as relações humanas e suas complexidades. Ela se apresenta como uma grande riqueza natural e possui valor não só ambiental, mas também social, econômico e cultural.

A vida humana depende do equilíbrio da biodiversidade, mas esta também não pode ser simplesmente preservada, ou seja, intocada, mas por ser intrinsecamente uma fonte de subsistência, é necessário o uso racional de seus recursos, prezando-se pela sua conservação. O desenvolvimento de vários produtos essenciais ao ser humano baseia-se nas riquezas biológicas, uma vez que a biodiversidade sofre um grande impacto, merecendo, portanto, a devida proteção.

Existem países ricos em biodiversidade que em sua maioria têm níveis de desenvolvimento baixo e não possuem estrutura econômica, social e científico-tecnológica para explorar de forma sustentável suas riquezas. A biodiversidade pode ser vista como seu instrumento garantidor de desenvolvimento, mas seus recursos são mal explorados ou são explorados por outros países que não distribuem de forma equitativa os benefícios colhidos.

Os contratos de bioprospecção são ilustrativos nesse conflito de interesses, pois são ferramentas pelas quais os países ricos em biodiversidade poderiam alcançar um nível de desenvolvimento pela exploração racional de seus recursos biológicos através da permissão de acesso aos mesmos a países pobres em diversidade biológica e ricos em tecnologia, capazes de recompensar tal uso de forma justa, através de repartição de benefícios advindos dos lucros dos produtos desenvolvidos e pela transferência de tecnologia. Entretanto, nem sempre tais contratos são construídos por esta base ideal, camuflando em verdade, práticas de biopirataria e apropriação indevida de conhecimentos tradicionais.

Tais práticas estão cada vez mais frequentes pelo fato de que os produtos farmacêuticos, alimentícios e cosméticos, produzidos pelos recursos genéticos e biológicos podem ser patenteados como invenção, o que garante lucros expressivos às empresas que realizam as atividades de bioprospecção. E como hoje o capitalismo impera, a busca pelo lucro ultrapassa a adoção de condutas éticas, que faz com que certas empresas busquem o crescimento financeiro sem a devida contraprestação pela utilização dos recursos biológicos, o que representa um grande prejuízo para os países ricos em biodiversidade e um risco à proteção da diversidade biológica. 
Neste sentido, pergunta-se: é possível alcançar um nível satisfatório de proteção da biodiversidade, incluindo-se a fauna e flora, nos contratos de bioprospecção por meio de uma reinterpretação da propriedade intelectual, especificamente uma reformulação de aspectos do sistema de patentes?

A hipótese trabalhada é que os contratos de bioprospecção camuflam uma apropriação indevida da biodiversidade e dos conhecimentos tradicionais, trazendo riscos à proteção da biodiversidade e prejuízos aos países detentores, que em sua maioria são subdesenvolvidos e necessitam de melhores condições tecnológicas para explorar autonomamente as suas riquezas químicas e biológicas.

Assim, considerando-se que as patentes desempenham um importante papel nos contratos de bioprospecção, como objetivo final e fonte maior de lucro sobre os produtos desenvolvidos com base em descobertas e aplicações de conhecimentos tradicionais, há a necessidade de aliar a propriedade intelectual, em especial as patentes, e os dispositivos da CDB para evitar que os contratos de bioprospecção se apresentem como um risco à proteção da biodiversidade.

Tendo em vista tal problema e tal hipótese, o artigo tem o objetivo central de analisar a possibilidade de se otimizar a proteção da biodiversidade dos contratos de bioprospecção por meio de adoção de medidas alternativas no sistema de patentes.

O tema justifica-se porque os contratos de bioprospecção podem camuflar verdadeiras práticas de biopirataria que se constituem em uma apropriação indevida da biodiversidade, representando uma ameaça a esta. Por isso, faz-se necessária uma discussão mais profunda acerca do tema, verificando-se a imperiosidade de que tal discussão tome rumos internacionais, tendo em vista a importância do sistema de patentes nas atividades de bioprospecção e o fato de que a propriedade intelectual é um instituto jurídico altamente internacionalizado e depende de cooperação científica, jurídica e tecnológica que extrapolam as fronteiras nacionais dos países.

A metodologia utilizada para se enfrentar o problema proposto é a indutiva-dedutiva, utilizando-se da pesquisa bibliográfica e breve análise de alguns casos concretos.

Primeiramente, aborda-se a relação entre biodiversidade, biotecnologia e propriedade intelectual. Após, analisa-se o conceito de contrato de bioprospecção, suas nuances e a abordagem de alguns casos concretos para ilustrar alguns problemas existentes em tal relação jurídica. Por fim, faz-se uma análise de propostas de medidas alternativas a serem aplicadas no sistema de patentes para minimizar os efeitos negativos dos contratos de bioprospecção. 


\section{BIODIVERSIDADE, BIOTECNOLOGIA E PROPRIEDADE INTELECTUAL}

A biodiversidade, a biotecnologia e a propriedade intelectual são conceitos que estão intrinsecamente ligados e desempenham um importante papel no desenvolvimento de novas tecnologias e produtos que proporcionam um maior bem-estar para a sociedade, mas ao mesmo tempo suscitam questões jurídicas, éticas, econômicas e sociais.

É inegável que o desenvolvimento do conhecimento técnico-científico trouxe muitas vantagens e melhorias na qualidade de vida do homem, como se observa na área da medicina com a produção de novos medicamentos e vacinas, a produção de organismos geneticamente modificados para aplicação na agricultura, na indústria alimentícia e na de cosméticos.

A biodiversidade é importante neste sentido, pois se constitui, muitas vezes, em matéria-prima para o desenvolvimento de produtos. A biodiversidade, segundo Vladmir Magalhães (2011), engloba diversos níveis de organização da vida e não diz respeito somente a um conjunto de componentes, mas também à forma como eles estão organizados e como se dão as interações entre si e os processos resultantes dessas interações. Ela evoca a vinculação existentes entre as espécies de fauna e flora e o seu nexo orgânico, em que cada ser vivo tem uma função essencial a exercer para a manutenção do todo, estando todos interconectados e interdependentes (MILARÉ, 2014).

Neste sentido, a biotecnologia é um ramo da ciência que utiliza conhecimentos interdisciplinares, tendo, como consequência, ampla aplicação principalmente nos setores ligados à medicina, à farmácia, à indústria de cosméticos, à indústria alimentícia, à agricultura, à pecuária e ao meio ambiente. Os processos e produtos advindos da biotecnologia passaram a ter um grande valor econômico, possuindo um considerável impacto no mercado, especialmente se considerarmos os enormes investimentos feitos em pesquisas biotecnológicas. "O potencial de ganhos econômicos da biotecnologia modificou as pesquisas científicas de um exercício primordialmente acadêmico para um exercício industrial e empreendedor" ${ }^{1}$. (GUNERATNE, 2012, p. 28; tradução nossa).

Neste âmbito, a propriedade intelectual se torna relevante, pois constitui-se num instrumento para possibilitar e legitimar a exploração econômica dos inventos, na medida em que as patentes concedidas garantem o direito exclusivo de exploração ao inventor.

Hoje a propriedade intelectual está atrelada à função social, já que é imprescindível que os bens produzidos pelo intelecto e criatividade humana visem os interesses sociais, o

\footnotetext{
${ }^{1}$ The potencial economic gains of biotechnology have transformed scientific research from a primaly academic exercise into a industrial and entrepreneurial one.
} 
progresso e o bem-estar da comunidade. Isso se torna especialmente claro quando se diz respeito à propriedade intelectual aplicada à biotecnologia, já que a utilização desta frequentemente está vinculada a setores de grande importância como o da saúde, da farmácia e o de alimentos, devendo o direito da propriedade intelectual encontrar um equilíbrio entre a necessidade de proteção do direito do inventor e a necessidade de acessibilidade à sociedade em geral.

É importante salientar, ademais, que a propriedade intelectual no campo da biotecnologia gera complexas discussões, principalmente no âmbito da ética, do direito, da economia e do meio ambiente. Vanessa Iacomini entende que:

\footnotetext{
A propriedade intelectual quando analisada no campo da biotecnologia, em especial a proteção pelo instrumento patentário, sustenta discussões em todo o mundo envolvendo a humanidade, independente de raça, sexo, religião, entendimento doutrinário ou político, pois a ideia de patentear seres vivos confronta-se diretamente com a questão ética, socioeconômica e até mesmo, cultural, diante dos limites da invenção e da inovação que são ultrapassados (IACOMINI, 2009, p. 13).
}

Tendo em vista as grandes questões que biotecnologia e a propriedade intelectual suscitam no tocante à biodiversidade, neste artigo analisar-se-á quais as medidas que podem ser utilizadas no sistema de patentes para otimizar os contratos de bioprospecção quanto à proteção da biodiversidade. Já que estes contratos, em alguns casos, camuflam a existência de biopirataria, o que representa uma ameaça à proteção da biodiversidade.

\section{CONTRATOS DE BIOPROSPECÇÃO E BIODIVERSIDADE}

Bioprospecção é uma atividade que envolve a exploração dos componentes da biodiversidade visando a descoberta, coleta e análise de recursos genéticos e biológicos que possuem valor econômico, podendo-se utilizar de conhecimentos tradicionais das comunidades locais. (SANT'ANA, 2004).

Marcelo Dias Varella (1998) explica que a bioprospecção é comum entre etnomologistas, biólogos, taxonomistas e até mesmo colecionadores. Salienta que atualmente essa atividade se destaca pelas práticas das empesas farmacêuticas, que buscam na biodiversidade princípios ativos que possam se tornar novos medicamentos, visando a produção mais barata, eficaz e inovadora, no sentido de encontrar novos tratamentos e curas para doenças.

Existem diversas técnicas de bioprospecção na indústria farmacêutica e Marcelo Dias Varella (1998) explica que a mais comum é a identificação de novas plantas não exploradas, 
seguida de verificação da existência de princípios ativos úteis e a aplicação destes em testes de doenças para avaliar o seu êxito ou não, para assim, dar início à fabricação de remédios. $\mathrm{O}$ autor continua explicando que os materiais biológicos estudados devem ser catalogados, para facilitar atividades de prospecção posteriores.

Existe a prospecção aleatória, na qual se utiliza de plantas ao acaso e a racional, que seleciona plantas e animais conforme a linhagem genética deduzida de características fenotípicas. A segunda forma de prospecção é a mais indicada para a atividade farmacêutica, já que essa atividade é muito custosa e o método aleatório não é muito eficiente por, dentre outros fatores, não se utilizar de conhecimentos tradicionais (VARELLA, 1998).

Buscando-se a eficiência da atividade de bioprospecção, o conhecimento tradicional é de grande valia, por isso utiliza-se frequentemente a etnobotânica, na qual analisa-se o uso de determinada planta por culturas indígenas e pela medicina tradicional. Isso porque se uma planta é utilizada, ela provavelmente possui alguma eficácia e consequentemente pode existir algum princípio ativo útil.

Nesse sentido, firmam-se acordos para que as atividades de bioprospecção sejam desenvolvidas. Os contratos de bioprospecção se referem "à coleta, troca e desenvolvimento comercial de recursos biológicos (...). Os acordos abrangem produtos farmacêuticos, agrícolas, botânicos, cosméticos e outros produtos industriais" (GOLLIN, 2004, p. 133).

Tais acordos devem estar consoantes às leis nacionais que são variadas dependendo do país onde ocorre a bioprospecção. Devem ser observadas leis sobre os acordos específicos, leis sobre propriedade intelectual, leis ambientais, dentre outras. Para Michael Gollin (2004), os contratos de bioprospecção de biodiversidade devem conter necessariamente a identificação das partes, os recursos que serão coletados e exportados, como será o regime de posse desses recursos, as compensações ou repartições de benefícios advindos do acesso, a transferência de tecnologia, as restrições de transferência a terceiros, medidas de conservação dos recursos biológicos, direitos de propriedade intelectual, incluindo, quando for o caso, direitos de sigilo e exclusividade.

Para o autor (GOLLIN, 2004), os contratos de bioprospecção possuem vários aspectos e devem observar uma diversidade de leis que variam de Estado para Estado e possuem uma singularidade que os deixam mais complexos, que é o fato de incluírem a biodiversidade como um de seus elementos, fator que esbarra em questões como a soberania e direitos fundamentais, sendo necessária também a observância de tratados internacionais como a Convenção sobre Diversidade Biológica de 1992 (CDB) (MINISTÉRIO DO MEIO AMBIENTE, 2000). 
Segundo Erivaldo Moreira Barbosa (2011), a CDB é um documento jurídiconormativo internacional que reconhece a importância da biodiversidade e a necessidade de sua conservação, incluindo-se o uso sustentável de seus recursos e a repartição justa e equitativa dos benefícios advindos desse uso. A CDB visa aliar a exploração da biodiversidade com o necessário desenvolvimento dos países pobres, que ainda enfrentam problemas estruturais, sociais, econômicos e políticos. Busca-se o desenvolvimento de tais países sendo que este, segundo Alaim Stefanello (2010), deve observar o princípio da dignidade da pessoa humana, garantindo às populações o direito de viver em um ambiente ecologicamente equilibrado, sem poluição e com acesso à água e alimentos de qualidade, garantindo-lhes também acesso a direitos culturais, sociais, políticos e civis.

Assim, a CDB apresenta um importante papel na consecução desses contratos, já que estabelece as diretrizes mínimas a serem observadas pelos países, o que mobiliza diversos Estados a modificar e regulamentar tais contratos a nível nacional, de forma a não ocorrer prejuízos.

O reconhecimento do direito soberano dos países aos seus recursos naturais possibilitou que os governos nacionais dos países determinassem regras sobre o acesso aos recursos genéticos, sujeitando-o à legislação nacional. $\mathrm{O}$ art. 15 da CDB prescreve que as partes contratantes devem criar condições para permitir o acesso a recursos genéticos e este, quando concedido, deve ser de comum acordo, sendo imprescindível o consentimento prévio do país provedor dos recursos.

Luiz Magno Bastos Júnior (2011) explica que essas regras têm apenas um caráter genérico e buscam garantir um mínimo de segurança aos países em desenvolvimento. Entretanto, o autor conclui que:

\footnotetext{
Esta margem de ductibilidade nas cláusulas assecuratórias, não obstante ter garantido a adaptabilidade dos acordos bilaterais às hipóteses experimentadas, possibilitou a sua concreta inobservância, ou pelo menos, minimizou os resultados pretendidos de viabilizar o pleno desenvolvimento econômico e social e a erradicação da pobreza nos países periféricos, à medida que as vantagens entre os contratantes são flagrantemente desproporcionais (BASTOS JÚNIOR, 2011, p. 196).
}

As vantagens são desproporcionais porque, conforme Marcelo Dias Varella salienta, “assim que absorvido, o conhecimento [tradicional] é transformado em commodities e vendido a cifras que muitas vezes atingem centenas de milhões de dólares. Na maioria das vezes inexiste qualquer contraprestação" (1998, p. 89). 
A maior parte dessas atividades é realizada em florestas de países em desenvolvimento ou subdesenvolvidos, onde há pouca fiscalização e onde se situam comunidades tradicionais que não nem noção do valor econômico da riqueza biológica do local onde vivem e do conhecimento ancestral que possuem.

Thomas Burelli explica que

essas atividades de bioprospecção se alimentam de numerosas esperanças de descobertas e de inovação nos domínios da biotecnologia, do agroalimentício, do farmacêutico, do ambiental ou até mesmo do cosmético. O acesso, a identificação e a utilização da biodiversidade constituem-se em questões cruciais. (2013, p. 1749; tradução nossa) ${ }^{2}$.

O autor evidencia o caráter econômico da atividade de bioprospecção, que pode ser utilizada em vários setores, mas que, por implicar no uso da biodiversidade, envolve questões complexas como a exploração indevida da diversidade biológica, a apropriação dos conhecimentos tradicionais, a falta de contraprestação das empresas e laboratórios pelos recursos retirados, frequentemente, de países subdesenvolvidos, o que agrava mais o abismo econômico entre os países "ricos" e "pobres", que por estes últimos não possuírem tecnologia adequadas, não podem sequer explorar sustentavelmente as riquezas biológicas que possuem.

Assim, "o crescimento da atividade bioprospectora fez nascer conflitos de diferentes espécies, de natureza econômica e cultural, envolvendo disputas entre países, organizações internacionais de defesa dos interesses indígenas e diversas entidades e grupos sociais" (BASTOS JÚNIOR, 2011, p. 187).

No próximo tópico, serão analisados alguns contratos de bioprospecção, onde será explicitado concretamente alguns problemas existentes em tais contratos para, a seguir, ser possível analisar os contratos de bioprospecção criticamente, avaliando a necessidade ou não de mudanças, principalmente no que tange ao regime de propriedade intelectual.

\subsection{Casos Concretos}

Neste tópico, analisar-se-ão alguns contratos de bioprospecção para ilustrar as suas nuances e implicações para aprofundar as críticas no último tópico.

\footnotetext{
${ }^{2}$ Ces activités de bioprospection alimentent de nombreux espoirs de découverte et d'innovation dans le domaines des biotechnologies, agroalimentaire, pharmaceutique, environmental ou encore cosmétique. L'accès, l'indentification et l'utilisation de la biodiversité constituent donc des enjeux cruciaux.
} 


\subsubsection{Novartis e Bioamazônia}

A Bioamazônia (Associação Brasileira para o Uso Sustentável da Biodiversidade da Amazônia) realizou um contrato com a indústria farmacêutica Novartis, da Suíça, que concedia a esta o direito de acessar exclusivamente o patrimônio genético amazônico, legando também a possibilidade de utilização de tais recursos. (NAVES; VASCONCELOS, 2015).

O contrato permitia que a Novartis coletasse, identificasse e classificasse os componentes químicos e biológicos dos elementos da biodiversidade, podendo enviá-los à Suíça para posteriores pesquisas. À Novartis foi concedido o direito exclusivo e perpétuo de exploração e comercialização de produtos, possibilitando a detenção de patentes e licenciamento a terceiros, sendo que a contraprestação dada ao Brasil era o pagamento pelo lapso temporal entre o início das pesquisas e o lançamento do produto final, além da transferência de tecnologia e capacitação de pesquisadores-técnicos (PENHA; MONT'ALVERNE, 2012).

O início e término das licenças eram declarados pela empresa suíça, o que dificultava a fiscalização. "Houve clara apropriação indébita da biodiversidade brasileira por uma transnacional, resultando em nítida privatização dos recursos genéticos" (PENHA; MONT'ALVERNE, 2012, p. 232).

Nesse sentido, Bruno Torquato de Oliveira Naves e Carlos Frederico Vasconcelos (2015) apontam que houve muitas irregularidades no contrato, salientando a perpetuidade da licença, a falta de repartição de benefícios concretos aos Estados e às comunidades tradicionais.

Houve outras críticas da comunidade científica, a começar pela escolha da empresa a explorar os recursos genéticos, que é estrangeira, sendo que deveria ter sido firmado um contrato com uma empresa brasileira, para fortalecer o desenvolvimento científico e farmacêutico.

Tal "oficialização" da biopirataria, depois de tantas controvérsias, foi interrompida quando a Novartis decidiu cancelar o contrato.

\subsubsection{The Body Shop}

A empresa inglesa The Body Shop realizou um contrato, no Brasil, com os índios Kayapós (ou Mebengokre) para a compra de óleo de castanhas para utilizar em seus produtos. A empresa seria a única compradora do óleo e assim, poderia estabelecer o preço e o montante de produto que iria adquirir (TURNER, 1995). 
Terence Turner (1995) explica que a contribuição de maior valor dada pelos Kayapós não é o óleo de castanhas, mas as suas imagens fotográficas, que servem como propaganda gratuita para a The Body Shop, que se mostra como empresa sustentável, sem que haja uma contraprestação pelo direito de imagem.

Marcelo Dias Varella (1998) explica que esse acordo feito diretamente com os índios não respeitou a legislação brasileira e nem teve autorização da FUNAI (Fundação Nacional do Índio).

Os Kayapós pressionaram a The Body Shop para que ela permitisse a expansão da produção do óleo para outras vilas e comunidades, o que foi recusado. Turner (1995) explica que tal situação é devida ao fato de que o verdadeiro interesse da empresa é o uso da imagem dos Kayapós como propaganda, sendo contrário ao seu interesse a permissão para expansão do mercado para os Kayapós.

A empresa faturou milhões e a contraprestação para os índios foi ínfima, o que levou à abertura de um processo, pelos índios, contra a empresa, alegando uso indevido de sua imagem e descumprimento do acordo. A The Body Shop alegou que os direitos de imagem estavam pagos porque a contraprestação dada aos índios pelo óleo estava acima do valor corrente internacional. Entretanto, conforme explica Marcelo Dias Varella (1998), somente os índios Kayapós possuem o conhecimento para produzir tal óleo, sendo que sua matéria-prima é típica da flora brasileira, não havendo comércio internacional deste produto.

Tal contrato é prejudicial pois há o aproveitamento do conhecimento tradicional sem a contraprestação como transferência de recursos, tecnologia ou incentivos para o desenvolvimento do país (VARELLA, 1998). Houve, portanto, uma exploração indevida dos conhecimentos tradicionais e de imagem da comunidade indígena, revelando um desequilíbrio entre os pólos envolvidos no contrato.

\subsubsection{Shaman Pharmaceuticals}

A Shaman Pharmaceuticals é uma empresa sediada nos Estados Unidos que realiza contratos de bioprospecção em países ricos em biodiversidade, firmando parcerias com tribos indígenas para compartilhamento de conhecimentos tradicionais. (VARELLA, 1998).

A Shaman compensa as tribos de forma monetária ou não pelo conhecimento e materiais biológicos fornecidos, sendo que muitas vezes o pagamento é adiantado, para satisfazer as comunidades indígenas e assegurar a sua confiança (VARELLA, 1998). 
Marcelo Dias Varella (1998) aponta que os acordos firmados pela empresa e as comunidades locais violam diversas prescrições legais, já que as comunidades indígenas não têm consciência do valor econômico dos recursos naturais localizados onde habitam e, assim, firmam contratos cuja contraprestação não é equitativa. O pagamento através de solução de necessidades básicas como atendimento médico ou satisfação de necessidades alimentícias são ínfimas se comparados com a riqueza que a Shaman pode adquirir com os recursos genéticos e o conhecimento tradicional associado. Neste sentido, o autor salienta,

\begin{abstract}
A empresa americana aproveita-se da ignorância dos índios para usufruir dos mesmos, transformando sua cultura em mercadoria, sem lhes explicar a real dimensão do fato. Por motivos óbvios, os índios ficam satisfeitos, desconhecem o valor da biodiversidade, precisam de alguns bens de uso imediato e se contentam com os mesmos. (VARELLA, 1998, p. 109).
\end{abstract}

Esses tipos de contratos que nascem travestidos de benevolência e preocupação com o desenvolvimento das comunidades indígenas, em realidade apresentam uma verdadeira apropriação ilegal da biodiversidade, gerando grandes prejuízos não só às comunidades tradicionais, mas ao Estado no qual se localizam, ao impossibilitar uma contraprestação equitativa pela riqueza biológica retirada.

\title{
4 CONTRATOS DE BIOPROSPECÇÃO E SISTEMA DE PATENTES: O QUE É NECESSÁRIO MUDAR?
}

Através da análise de alguns casos concretos de bioprospecção, percebe-se que é evidente o risco que este pode causar na perda da biodiversidade pela biopirataria e pela apropriação indevida de conhecimentos tradicionais. Sem medidas jurídicas e econômicas fortes e adequadas, os contratos de bioprospecção podem se transformar em verdadeiras ameaças à proteção da biodiversidade.

Marcelo Dias Varella (1998) faz uma análise crítica dos contratos de bioprospecção, entendendo que os mesmos não satisfazem as condições mínimas para se garantir o desenvolvimento de países subdesenvolvidos, já que não há efetiva transferência de tecnologia ou de recursos financeiros, nem mesmo distribuição igualitária de royalties pelos produtos desenvolvidos ou menção à co-patenteamento entre a empresa bioprospectora e os cientistas locais.

A biopirataria também é um risco que os países fornecedores de biodiversidade correm ao possibilitar as atividades de bioprospecção em seus territórios. A biopirataria pode ser 
entendida como uma apropriação indevida de organismos biológicos, na qual as espécies de flora e fauna tradicionalmente cultivadas por populações indígenas, são coletadas e patenteadas por empresas ou laboratórios, sem que estas ofertem uma contraprestação adequada ou direitos de propriedade às comunidades tradicionais. (KELTER, 2014).

A ocorrência da biopirataria é um risco nas atividades de bioprospecção pois os seus contratos podem camuflar uma verdadeira apropriação indébita, quando os termos contratuais não são condizentes à $\mathrm{CDB}$ ou quando a contraprestação dada às comunidades indígenas é ínfima, já que se aproveita da ingenuidade dos indivíduos, que desconhecem o real valor da riqueza que possuem.

Para frear a biopirataria, de acordo com Ana Flávia Platiau e Marcelo Dias Varella (1999) é necessário o fortalecimento da legislação nacional do país fornecedor de biodiversidade, de forma a regularizar e fiscalizar efetivamente o acesso aos recursos genéticos e também a solidariedade internacional para criar instrumentos e mecanismos para a cooperação científica e compartilhamento de benefícios para os contratantes.

Outro problema enfrentado é o fato de que os países subdesenvolvidos possuem muitas dificuldades econômicas, sociais, políticas e estruturais o que faz com que eles aceitem propostas que, camufladas por termos razoáveis que trazem benefícios mínimos, trazem em verdade vantagens desiguais para as partes contratantes (VARELLA, 1998).

Neste sentido,

Enquanto forem mantidos incólumes os contratos bilaterais ou setorizados de bioprospecção, estas disparidades persistirão, em face da quase-inexistência de poder de barganha dos países de origem, uma vez que, muitas vezes, dispõem somente dos recursos orgânicos que, desprovidos da tecnologia, massa crítica, investimentos volumosos, não significam nada além de "mato", como comumente o vêem os caboclos amazônicos ou os nativos africanos das florestas do Alto Congo (BASTOS JÚNIOR, 2011, p. 201).

À luz dessas críticas, é necessário se averiguar de que forma os contratos de bioprospecção podem ser efetivados sem prejuízo da proteção da biodiversidade, sendo que as práticas econômicas envolvendo a biodiversidade devem, necessariamente, estar em consonância com a CDB.

Nesse sentido, a propriedade intelectual representa um importante papel, já que o maior interesse das empresas bioprospectoras é a aquisição de patentes e dessa forma, através da interpretação e adoção de novas medidas a respeito do instituto das patentes, é possível minimizar os impactos negativos dos contratos de bioprospecção. 
Graham Dutfield (2004) explica que existem teorias que acreditam que as patentes são necessárias para a efetiva repartição de benefícios nos contratos de bioprospecção. Isso porque as patentes permitiriam uma difusão de conhecimentos, além de constituírem-se em incentivos para o desenvolvimento e investimento em invenções e poderem ser compartilhadas através de licenciamentos.

Entretanto, Dutfield (2004) alerta que esses benefícios são vistos na teoria, mas não na prática, já que os mesmos não são compartilhados por todas as partes nos contratos de bioprospecção, porque as comunidades tradicionais não usufruem dos direitos de propriedade sobre o seu conhecimento, que é valioso.

Ademais, as patentes sobre elementos da biodiversidade muitas vezes não se constituem em verdadeiras invenções, mas em descobertas, o que denigre todo o sistema de patentes. Graham Dutfield (2004) explica que há problemas na qualidade das patentes, já que o volume de solicitações é grande e não há um controle rigoroso dos requisitos de patenteabilidade. Muitas vezes não há invenção, apenas reformulação de um conhecimento tradicional, possibilitando que "pessoas copiem o conhecimento estrangeiro não documentado e reivindiquem-no como uma nova invenção" (DUTFIELD, 2004, p. 72).

Mesmo sob esse quadro problemático, as patentes ainda são vistas como um objeto fundamental nos contratos de bioprospecção, fazendo com que alguns autores afirmem que a reformulação de alguns aspectos do direito das patentes auxiliará na proteção da biodiversidade e na facilitação da distribuição equitativa de benefícios.

Graham Dutfield entende ser um caminho difícil a busca pela solução através do sistema de patentes, tendo em vista as constantes críticas que o mesmo sofre. Entretanto, é imperioso "que se invista significativamente na melhoria da qualidade das patentes, que por si só ajudaria a aplacar os temores de que o sistema de patentes, em sua atual situação, se choque com o princípio da repartição eqüitativa de benefícios, no contexto dos recursos genéticos e conhecimento tradicional associado" (2004, p. 88). Assim, é necessário que o próprio sistema de patentes construa uma confiança entre os fornecedores de recursos biológicos e genéticos e os seus consumidores e usuários.

Algumas medidas que podem ser adotadas no tocante à propriedade intelectual, especificamente nas patentes, para minimizar os efeitos negativos que podem advir de alguns contratos de bioprospecção são a divulgação da origem dos recursos biológicos e do conhecimento tradicional associado a eles, o estabelecimento da demonstração inequívoca da adequação do processo de desenvolvimento de um invento patenteável com as regras da CDB como requisito de concessão de uma patente biotecnológica, a criação de um banco de dados 
sobre conhecimento tradicional, e o reconhecimento do conhecimento tradicional como estado da técnica.

A Diretiva 98/44/CE, relativa a proteção jurídica das invenções biotecnológicas, da União Europeia, promulgada em 1998, estabelece, no preâmbulo do n. 27, que:

\begin{abstract}
Considerando que, cuando una invención tenga por objeto una materia biológica de origen vegetal o animal o que utilice una materia de este tipo, la descripción relativa a dicha invención deberá incluir, em su caso, información sobre el lugar geográfico de origen de dicha materia, cuando éste sea conocido, y ello sin perjuicio del examen de las solicitudes de patente y de la validez de los derechos que deriven de las patentes expedidas; (COMUNIDADES EUROPEAS, 1998, p. 15).
\end{abstract}

Essa Diretiva explicita uma das soluções encontradas no sistema de patentes, que é a divulgação da origem da matéria biológica objeto da patente que auxiliaria no objetivo da CDB de repartição justa e equitativa de benefícios entre o bioprospector e o fornecedor de biodiversidade. Graham Dutfield (2004) entende que essa diretriz pode ser adotada pelos países de forma branda, como um incentivo, ou mais incisiva, quando o país adota a obrigação de divulgação, citando como exemplo a Bélgica, que em 2000 colocou tal exigência no Ato Belga de Patentes. Outro país que tem previsão semelhante é a Suíça, que em sua lei sobre patentes de invenção, Lei no $232.14 / 54$, estabelece que os requerentes a patentes devem indicar no pedido a origem do recurso genético acessado, assim como a origem do conhecimento tradicional (SUISSE, 2012).

A divulgação da origem dos recursos genéticos e do conhecimento tradicional associado a ele requer, em suma, que os requerentes a patentes provem que os recursos utilizados na invenção a ser patenteada tenham sido adquiridos conforme as regras de acesso, repartição de benefícios, havendo consentimento prévio e mútuo acordo (GUNERATNE, 2012).

Camena Guneratne (2012) explica que a divulgação da origem dos recursos deve apresentar certas informações como: o país de origem e a fonte dos recursos biológicos e conhecimento tradicional; evidências de que houve consentimento prévio e informado, aprovado pelas autoridades nacionais; provas de que os acordos de repartição de benefícios e transferência de tecnologia foram feitos de acordo com as leis do país fornecedor.

Frederick Abbott (2006) entende que essa divulgação da localização geográfica da origem dos recursos genéticos objeto das patentes contribuiria na análise dos requisitos destas, como o ato inventivo e a novidade, pois daria mais substrato à verificação do estado da técnica anterior ao pedido de patente e também a averiguação se o objeto é uma descoberta ou 
verdadeiramente uma invenção. Tal medida contribui para uma maior qualidade das patentes concedidas.

Nesse sentido, Camena Guneratne (2012) explica que essa medida garante transparência, equidade e evita a apropriação indevida de recursos biológicos, pois melhora o exame das patentes e impede práticas de biopirataria. Assim, este sistema garantiria um maior fluxo de recursos genéticos entre países provedores e usuários, pois asseguraria maior segurança e confiança, possibilitando a concretização do objetivo da CDB.

Ao divulgar a origem geográfica do material genético auxilia-se na avaliação do processo de bioprospecção para a produção do invento, questionando-se se o mesmo respeitou a legislação local acerca da propriedade intelectual (ABBOTT, 2006). Além disso, seria possível citar os países de origem dos recursos para participar do processo e trazer informações e intervenções relevantes, garantindo um acesso mais democrático ao país fornecedor de biodiversidade.

Ademais, Frederick Abbott (2006) explica que a divulgação da origem geográfica dos recursos genéticos é benéfica no sentido de que determina que o requerente da patente demonstre que possui o direito propriedade sobre a invenção, tendo em vista que os países detêm a propriedade dos recursos genéticos localizados em seu território. Assim, uma invenção que utilize um material genético pressuporia uma transferência de propriedade ou consentimento no uso de tais recursos, demandando que o requerente da patente apresente os meios com os quais ele adquiriu o direito de propriedade ou o consentimento para uso do recurso.

Isso inviabilizaria a apropriação indevida de recursos genéticos sem o consentimento do Estado, sendo um instrumento contra a biopirataria e facilitaria a transferência de tecnologia aos países detentores de biodiversidade.

Desta forma, Frederick Abbott (2006) compreende que acordos multilaterais para incentivar tal divulgação seriam benéficos, mas não suficientes para solucionar, sozinhos, os problemas dos contratos de bioprospecção, mas poderia reduzir a frequência de concessão de patentes problemáticas, que se apresentam como apropriação indevida de conhecimentos e descobertas, sem trazerem em si uma verdadeira invenção.

Existe também a possibilidade de, no pedido da patente, haja o requisito de se demonstrar a conformação do processo de produção do invento patenteável com os dispositivos da $\mathrm{CDB}$, principalmente o compartilhamento equitativo de benefícios, e as leis do país de origem dos recursos genéticos (ABBOTT, 2006). 
Como outra forma de otimizar a qualidade das patentes concedidas, Graham Dutfield (2004) aponta que a Índia iniciou um projeto de solicitação de criação de um banco de dados sobre conhecimento tradicional, que poderiam ser usados para otimizar a eficiência das pesquisas sobre conhecimentos já adquiridos. Assim, é possível averiguar se determinada patente se apropriou indebitamente de um conhecimento tradicional, ou seja, de um método para chegar a determinado produto ou solução, impossibilitando ou invalidando a sua concessão.

Por fim, tem-se a possibilidade de se reconhecer os conhecimentos tradicionais como estado da técnica. A importância do conhecimento tradicional nas patentes e, consequentemente o interesse da sua utilização em práticas de bioprospecção, está no fato de que ele pode dar substrato a uma invenção. Camena Guneratne (2012) explica que o conhecimento tradicional pode ser relevante para a novidade e atividade inventiva de uma invenção, que são requisitos das patentes, já que a invenção não pode ser fruto de um conhecimento que já está no estado da técnica, ou seja, é conhecido e pode ser acessado, ela tem que ser inédita e criativa.

Assim, alguns países em desenvolvimento entendem que o sistema de patentes pode auxiliar na apropriação indébita e utilização sem autorização de conhecimentos tradicionais ao conceder patentes que se baseiam neles, já que os conhecimentos tradicionais não são reconhecidos como saber pertencente ao estado da técnica (GUNERATNE, 2012). Assim, questiona-se a qualidade e idoneidade das patentes baseadas em conhecimento tradicional, já que este, como saber existente, não pode ser considerado como novo, sendo indevida a concessão de um benefício para um indivíduo que não atuou totalmente na criação de seu invento.

Desta forma, reconhecer o conhecimento tradicional como estado da técnica possibilita que se refute a existência do requisito novidade da invenção, caso esta esteja baseada em um saber tradicional. O problema que se tem é que o conhecimento tradicional é um bem intangível e está baseado em tradições não escritas, o que dificulta a sua análise como conhecimento no estado da técnica. Isso porque vários países, como os EUA, somente consideram como estado da técnica o conhecimento escrito (GUNERATNE, 2012).

O fato é que o conhecimento tradicional muitas vezes é inacessível ou de difícil determinação, contudo, o reconhecimento legal do conhecimento tradicional sendo escrito ou não escrito é um importante passo para a sua proteção, apesar de ser difícil a sua consecução (GUNERATNE, 2012).

A documentação do conhecimento tradicional seria uma forma trabalhosa, porém idônea para que seja revelado à população e aos examinadores das patentes a existência desse 
conhecimento e impedir a apropriação indevida e a concessão de patentes sem que os povos que detém esse saber usufruam dos benefícios advindos da exploração da invenção (GUNERATNE, 2012).

Assim, percebe-se que existem medidas que podem ser adotadas no sistema de patentes para melhorar a sua relação com a biodiversidade e a necessidade de compartilhamento de benefícios e transferência de tecnologia. Tais medidas alternativas podem se tornar uma importante ferramenta para a proteção da biodiversidade nos contratos de bioprospecção, já que implicaria numa maior qualidade das patentes concedidas, averiguando se estas estão consoantes à CDB. Para tal feito é necessário que se faça uma cooperação internacional e uma ampla discussão, para que se possa alterar os pilares do sistema internacional de patentes, materializados no TRIPS (Trade Related Aspects of Intellectual Property), permitindo uma maior flexibilidade e adequação às necessidades dos países ricos em biodiversidade e carentes em desenvolvimento econômico, social e principalmente tecnológico.

Contudo, somente uma reformulação do sistema de patentes não é suficiente, principalmente pela dificuldade em se chegar a acordos em nível internacional tendo em vista o choque de interesses conflitantes. Luiz Magno Bastos Júnior (2011) também entende que somente os instrumentos legais não são suficientes já que a necessidade premente da sociedade é a intensificação do debate acerca dessa temática e a conscientização dos países provedores de recursos genéticos e biológicos da potencialidade e do valor que esses possuem.

Assim, a proteção da biodiversidade no tocante aos contratos de bioprospecção necessita de uma legislação nacional forte, aliada a uma efetiva fiscalização, de modo a estabelecer minuciosamente os parâmetros pelos quais os contratos devem se adequar, levandose em conta sempre as peculiaridades e necessidades dos países fornecedores de biodiversidade.

\section{CONCLUSÃO}

O presente trabalho teve como objeto de estudo central os contratos de bioprospecção e a biodiversidade, abordando, neste contexto, o papel das patentes no alcance de modelos mais justos no qual é possível proteger a biodiversidade e garantir uma distribuição equitativa de benefícios entre os países envolvidos nos contratos.

A riqueza da biodiversidade e a sua aplicação prática são muito importantes para a manutenção do equilíbrio da biosfera e para a garantia de melhores condições de vida à população. Com o descobrimento do valor dos recursos genéticos, através do advento da 
biotecnologia, o apelo econômico das invenções baseadas em seres vivos gerou um enorme interesse na busca por patentes, que concedem um direito de exclusividade de exploração.

Assim, para desenvolver determinados produtos, é necessária uma ampla pesquisa, que deve ser feita no local onde se encontram os recursos genéticos, sendo escolhidos frequentemente países ricos em biodiversidade para realizar contratos de bioprospecção. Esses, se idealmente realizados conforme a $\mathrm{CDB}$, possibilitariam uma justa distribuição de benefícios entre países, garantindo um uso racional e sustentável da biodiversidade.

Entretanto, a realidade é que tais contratos geram muitos prejuízos a países ricos em biodiversidade que necessitam de recursos financeiros e acabam aceitando tais atividades em seu território em troca de benefícios ínfimos, que não condizem com o valor do recurso explorado pela empresa ou laboratório bioprospector. Enquanto estes ficam com todo o lucro advindo da exploração de patentes.

Reconhecendo a importância que as patentes possuem como incentivo aos contratos de bioprospecção, conclui-se que é necessário adotar medidas alternativas para aliar a proteção dos direitos intelectuais com a $\mathrm{CDB}$ e os interesses dos países fornecedores de recursos genéticos e biológicos.

Alternativas como a divulgação das origens geográficas dos recursos utilizados nos inventos patenteáveis, a explicação de como o requerente das patentes adquiriu os direitos de propriedade sobre os recursos genéticos, a criação de bancos de dados sobre o conhecimento tradicional associado e o reconhecimento deste como estado da técnica são medidas que contribuirão para uma maior qualidade na averiguação das patentes. Ao possibilitar tal divulgação, estará claro quais os países que fizeram parte da produção de tal invento, facilitando que os países fornecedores dos insumos biológicos e genéticos reivindiquem a repartição de benefícios ou a sua co-autoria na produção do invento patenteável, dificultando a ocorrência de biopirataria.

Entretanto, tais medidas não são suficientes sem uma adequada legislação nacional de acesso aos recursos biológicos. A CDB já garantiu a soberania dos Estados sobre a sua riqueza biológica e genética, cabendo a estes adequar a legislação conforme suas peculiaridades e necessidades, salientando-se a importância do fortalecimento da fiscalização de tais contratos para haver uma proteção mais idônea à biodiversidade.

\section{REFERÊNCIAS}

ABBOTT, Frederick M. Patents, biotechnology and human rights: the preservation of biodiverse resources for future generations. Biotechnologies and International Human 
Rights, F. Francioni, ed., Hart Publishing, p. 315-331. Jan. 2006. Disponível em: < http://papers.ssrn.com/sol3/papers.cfm?abstract_id=1922851>. Acesso em: 02 dez. 2015.

ANTUNES, Paulo de Bessa. Direito ambiental. 16. ed. São Paulo: Atlas, 2014. 1420p.

BARBOSA, Erivaldo Moreira. Direito ambiental e dos recursos naturais: biodiversidade, petróleo e águas. Belo Horizonte: Fórum, 2011. 297p.

BASTOS JÚNIOR, Luiz Magno Pinto. A convenção sobre diversidade biológica e os instrumentos de controle das atividades ilegais de bioprospecção. In: MILARÉ, Édis; MACHADO, Paulo Affonso Leme (orgs.). Doutrinas essenciais - direito ambiental: volume IV - direito ambiental internacional e temas atuais. São Paulo: Revista dos Tribunais, 2011. p. 183-212.

BURELLI, Thomas. La bioprospection dans l'outre-mer français: opportunités et limites des dispositifs de régulation émergents dans l'outre-mer français. Revue de la Recherche Juridique: Droit Prospectif, Marseille, n. 04, p. 1745-1787. 2013. Disponível em: < http://papers.ssrn.com/sol3/papers.cfm?abstract_id=2478410 >. Acesso em: 29 nov. 2015.

COMUNIDADES EUROPEAS. Directiva 98/44/CE del Parlamento Europeo y del Consejo de 6 de julio de 1998: relativa a la protección jurídica de las invenciones biotecnológicas.

Diário Oficial de las Comunidades Europeas, Espanha, 1998. Disponível em: < http://www.wipo.int/edocs/mdocs/tk/es/wipo_grtkf_ic_1/wipo_grtkf_ic_1_8-annex1.pdf>. Acesso em: 02 dez. 2015.

DUTFIELD, Graham. Repartindo benefícios da biodiversidade: qual o papel das patentes? In: PLATIAU, Ana Flávia Barros; VARELLA, Marcelo Dias. Diversidade biológica e conhecimentos tradicionais. Belo Horizonte: Del Rey, 2004. p. 57-108.

GOLLIN, Michael A. Elementos de acordos comerciais de prospecção de biodiversidade. In: PLATIAU, Ana Flávia Barros; VARELLA, Marcelo Dias. Diversidade biológica e conhecimentos tradicionais. Belo Horizonte: Del Rey, 2004. p. 133-162.

GUNERATNE, Camena. Genetic resources, equity and international law. Massachusetts: Edward Elgar Publishing, 2012. 323p.

IACOMINI, Vanessa. Os direitos de propriedade intelectual e a biotecnologia. In: IACOMINI, Vanessa (Coord.). Propriedade intelectual e biotecnologia. Curitiba: Juruá, 2009. p. 13-29.

KELTER, Katherine A. Pirate patents: arguing for improved biopiracy prevention and protection of indigenous rights through a new legislative model. Suffolk University Law Review, v. 47, n. 2, p. 1-29. 2014. Disponível em: < http://vlex.com/vid/pirate-patentsarguing-for-542003758>. Acesso em: 29 nov. 2015.

MAGALHÃES, Vladmir Garcia. Propriedade Intelectual: biotecnologia e biodiversidade. São Paulo: Fiuza, 2011. 243p.

MEINERS, Constance Marie Milward de Azevedo. Patentes farmacêuticas e saúde pública: desafios à política brasileira de acesso ao tratamento anti-retroviral. Cad. Saúde Pública, Rio 
de Janeiro, vol. 24, n. 7, p. 1467-1478, jul. 2008. Disponível em: < http://www.scielo.br/scielo.php?pid=S0102-311X2008000700002\&script=sci_arttext >. Acesso em: 23 nov. 2015.

MILARÉ, Édis. Direito do Ambiente. 9. ed. São Paulo: Revista dos Tribunais, 2014. 1680p.

MINISTÉRIO DO MEIO AMBIENTE. Convenção sobre diversidade biológica - CDB: cópia do Decreto Legislativo no. 2, de 5 de junho de 1992. Brasília: Centro de Informação e Documentação, 2000. Disponível em: <

http://www.mma.gov.br/estruturas/sbf_dpg/_arquivos/cdbport.pdf>. Acesso em: 23 nov. 2015 .

NAVES, Bruno Torquato de Oliveira; VASCONCELOS, Carlos Frederico Saraiva de. Liberdade de pesquisa e proteção da propriedade intelectual: biodireito e bioética ambiental como formas de tutela do patrimônio genético nacional. In: NAVES, Bruno Torquato de Oliveira; OLIVEIRA, Camila Martins de; RAMOS, Ana Virgínia Gabrich Fonseca Freire (Coord.). Bioética ambiental e direito: coleção diálogos sobre meio ambiente - volume II. Belo Horizonte: Arraes, 2015. p. 175-190.

PENHA, Giovanna Burgos Ribeiro da; MONT'ALVERNE, Tarin Cristino Frota. Brasil pósNagoya: medidas para o cerco a biopirataria. Revista de Direito Internacional Econômico e Tributário, Brasília, v. 7, n. 2, p. 219-259, jul-dez 2012. Disponível em: < http://portalrevistas.ucb.br/index.php/RDIET/article/viewFile/4645/2909>. Acesso em: 29 nov. 2015.

PLATIAU, Ana Flávia Granja Barros; VARELLA, Marcelo Dias. Acesso aos recursos genéticos, transferência de tecnologia e bioprospecção. Revista Brasileira de Política Internacional, Brasília, v. 42, n. 2, jul-dec. 1999. p. 81-98. Disponível em: < http://www.scielo.br/pdf/rbpi/v42n2/v42n2a05.pdf>. Acesso em: 28 nov. 2015.

SANT'ANA, Paulo José Péret. A bioprospecção e a legislação de acesso a recursos genéticos no Brasil. In: PLATIAU, Ana Flávia Barros; VARELLA, Marcelo Dias. Diversidade biológica e conhecimentos tradicionais. Belo Horizonte: Del Rey, 2004. p. 229-254.

STEFANELLO, Alaim Giovani Fortes. Diálogos entre direitos humanos, sociobiodiversidade e propriedade intelectual. Veredas do Direito, Belo Horizonte, v. 7, n. 13/14, p. 27-56. 2010. Disponível em: <

http://www.domhelder.edu.br/revista/index.php/veredas/article/view/23/146>. Acesso em: 02 dez. 2015.

SUISSE. Loi n. 232.14 du 25 juin 1954. Loi fédérale sur les brevets d'invention. Etat le 1 janvier 2012. Disponível em: < https://www.admin.ch/opc/fr/classifiedcompilation/19540108/201201010000/232.14.pdf>. Acesso em: 15 fev. 2016.

TURNER, Terence. Neoliberal ecopolitics and indigenous peoples: the Kayapo, the "rainforest harvest", and The Body Shop. In: DICUM, Greg. Local heritage in the changing tropics: innovative strategies for natural resource management and control. Yale University: Bulletin Number 98, 1995. Disponível em: <http://environment.yale.edu/publicationseries/documents/downloads/0-9/98turner.pdf>. Acesso em: 30 mar. 2016. 
VARELLA, Marcelo Dias. Viabilização de mecanismos de troca: biodiversidade $\mathbf{x}$ desenvolvimento. Dissertação (Mestrado em Direito) - Universidade Federal de Santa Catarina, Florianópolis. 1998. 187f.

WORLD INTELLECTUAL PROPERTY ORGANIZATION. Convention establishing the World Intellectual Property Organization. Signed at Stockholm on July 14, 1967 and as amended on September 28, 1979. Disponível em:

<http://www.wipo.int/treaties/en/text.jsp?file_id=283854>. Acesso em: 23 nov. 2015. 